\title{
Genetic Counseling and Genetic Tests Ethical Challenges
}

Bereshneh AH, Nejad AS and Akrami SM*

Department of Medical Genetics, School of Medicine, Tehran University of Medical Sciences, Tehran, Iran

*Corresponding author: Akrami SM, Department of Medical Genetics, School of Medicine, Tehran University of Medical Sciences, Poursina St, Tehran, Iran, Tel: +98-21-88953005; Email: akramism@tums.ac.ir

Received date: August 11, 2015; Accepted date: September 15, 2015; Published date: September 20, 2015

Copyright: $@ 2015$ Akrami SM. This is an open-access article distributed under the terms of the Creative Commons Attribution License, which permits unrestricted use, distribution, and reproduction in any medium, provided the original author and source are credited.

\begin{abstract}
Practice standards in medical genetics provide an implied guide to the ethical, legal, and social implications of genetic tests. The public use of nondirective counseling reflects the principle that many testing choices should be determined by personal values.

Rising knowledge about the genetics of disease is generating remarkable ethical dilemmas for genetic services. The clinical purposes for genetic testing are increasing as well. Along with diagnosing disease, some genetic tests can identify inherited susceptibility to future disease, making it possible to modify anticipation and prevention strategies individually. Genetic profiling may also ultimately provide a means to optimize drug treatments.

In this review will discuss about genetic counseling, Types of genetic testing and also the importance of genetic services in the health policies. In addition, talk about Ethics Science in Biomedicine and criteria which concern with Autonomy Informed, Decision Informed and Consent confidentiality of results in Genetic services. In continue; focus on Screening, Genetics Tests and Social Rights; Genetics Tests and insurance companies; Genetic Tests and Involvement of other family members; Ethical challenges in Postnatal diagnosis, Prenatal diagnosis, Genetic counseling and consanguineous marriage.

Ultimately, the medical genetics community plays a key role in the management of ethical challenges of genetic services, however multidisciplinary approach is needed. Cultural, social, economical conditions and religion must be addressed in solving this dilemmas.
\end{abstract}

Keywords: Ethical issues; Genetic counseling; Genetic tests

\section{Introduction}

With respect to the heritability nature of diseases and the appearance of specific disorders in specific population groups, there have always been interests in the exploration of nature of human diseases and the need to solve complicated puzzle of hereditary diseases throughout time has led to the creation of a new medical branch called Medical Genetics. Commensurate with these achievements, various unknown issues will arise which may threaten the privacy of individuals [1]. Genetic science development and application has had beneficial results for medicine and has also given rise to legal and moral challenges [2].

\section{Genetic Counseling}

Various definitions on genetic counseling has been presented since it was first defined by Sheldon Reed in 1947. The National Society of Genetic Counselors has defined genetic counseling as a process in aiding people to comprehend and adapt to the medical, psychological and familial implications of genetic contribution to diseases [3].

Centers which offer genetic counseling are effective in enhancing healthcare systems and coordinating genetics knowledge into public health policies. Recent findings conclude a vital need for genetic counseling as an important tool for the implementation of genetic disorders prevention strategies [4].

\section{Common Criteria to Refer Patient for Genetic Counseling}

- A person with a known genetic condition within their family, in order to know about the risks that threatens their family and/or those of offspring.

- Parents who have children with genetic defects, referred for a possible diagnosis.

- A person with an intense family history of cancer, it is necessary to know increased risks and relevant options.

- A person with a known genetic condition willing to see an expert counselor to understand more about their condition.

- A person with potential genetic defects in the family wanting to know if a diagnosis is available, along with relevant risks and options.

- A pregnant couple with abnormal test results, wanting to know more about the abnormalities and the options which are available for them [5].

Based on our study; for a period of 4 years, 2,868 couples were enrolled to a research project. Data indicated that $85 \%$ of these couples had consanguineous relationships [3]. The most popular reasons for genetic counseling were premarital counseling $(80 \%)$, consanguinity (89\%), preconception (12\%), postnatal (7\%) and prenatal counseling (1\%). The most common complications in probands or related individuals were intellectual and developmental disorders such as 
hearing disorders and neuromuscular dystrophies. A history of family medical issues and/or consanguinity was causative of referrals for most families $[3,4]$.

\section{Types of Genetic Testing}

\section{Diagnostic testing}

Genetic testing is done on a person with symptomatic for approved and rejected genetic conditions.

\section{Predictive testing}

Genetic testing on a healthy relative at high-risk for monogenic disorder with specific later-onset.

\section{Susceptibility testing (risk profiling)}

A genetic test of one or more genetic marker with purpose to identify risks such as increased or decreased multifactorial conditions in a healthy person.

\section{Pharmacogenetic testing}

Testing for a genetic susceptibility for drugs with noxious reactions or for the drug effects in the treatment of individuals with a given genotype.

\section{Carrier testing}

This genetic test can detect a gene mutation which commonly has no adverse effects or results on the health of an individual.

\section{Prenatal testing}

A genetic test for a pregnant person, where genetic counselors suspect increased risks for a certain condition in the fetus during the pregnancy.

\section{Pre implantation genetic diagnosis}

Testing one or two cells of blastocyte in order to detecting the presence of point mutations and chromosomal rearrangements in a family with positive history of Mendelian or chromosomal disorders, in order to select the unaffected embryos to be implanted.

\section{Genetic screening}

These tests are for individuals and families who are not at high-risk but is offered to the common population or a specific group consistently [6].

\section{The Importance of Genetics Counseling and Genetic Tests}

Diagnosis in medical genetics is vital due to the fact that at least $10 \%$ of sperm and $25 \%$ of mature oocytes have chromosome abnormality and about $20 \%$ of all known pregnancies end in spontaneous abortion. About $50 \%$ of all spontaneous abortions in first trimester have chromosome abnormalities. Moreover, about 2-3\% of infants have congenital malformations where genetic factors are evident in more than half of them. $5-10 \%$ of common cancers are genetically based. There are over 21,000 diseases and single-gene traits registered up to now in OMIM. Over 500 metabolic disorders with genetic origin have been reported. There have been diseases reported with associated risks increase with parents' age and without genetic diagnosis, the numbers of individuals suffering from such diseases are increasing. Many diseases associated with learning difficulties have a genetic basis [1].

\section{Ethics Science in Biomedicine}

Ethics is a recently well-developed branch of knowledge that is related to ethical principles, standards of conduct, and correct/ incorrect regulations [7]. Traditionally, reference material is based on the analysis of society's philosophical and religious perspectives. In this case, the law applied by previous generations as logical inference constitutes accepted professional guidelines and regulations. It is debatable that there are no defined ethical and conscience tenets [8]. In more complex and controversial situations that are inconsistent with ethical principles, appropriate decisions and actions must be based on rights and responsibilities [8,9]. Ethical issues arise in all branches of medicine [10], but due to the vast nature of the genetics field in societies and relevant information which is rooted in the history and background of individuals, this subject is of particular importance and there are still question marks on many applicable aspects [10,11]. In the public mind, clinical genetics and genetics counseling is easily mistaken with eugenics which is the knowledge of improving species through reproduction. It is emphasized that clinical genetics does not have any thing in common with eugenics' unacceptable philosophies and there is no place for eugenics obligations [12]. 5\% of the human genome project's main budget is dedicated to studies on applicable ethical and social issues obtained from the project which is an indication of the importance of this issue and its effects on patient's various legal and medical aspects [13].

In this paper, some of the most controversial issues of genetic tests and basic principle of genetic counseling are described. It will soon be clear that there are no correct or incorrect approaches for these issues and experts' perspectives are widely different [14]. In some cases, the best result is to come to an agreement with explicit respect for either side's contradicting views and to allow patients to express their conscientious expectations. Awareness of ethical issues has increased proportionally to new genetics developments which has impact on society and causes new unknowns to arise $[14,15]$. Therefore, there are necessities towards some limitations and support systems for legal validation [15]. During pre and postnatal genetic tests, it is necessary to review patient's medical records and patients' history along with hereditary risk factors of disease transmission [14]. This is done through genetic counseling, which is a non-judgmental and nondirective communication process whereby accurate and comprehensive information is obtained to facilitate informed personal choices [16].

Physicians who interact with affected children are faced with a dilemma. On one hand, they aid in society survival and reproduction along with increasing 'bad genes' which supports the genetic future of humanity. Such behavior can be interpreted as dysgenics. On the other hand, many medical experts believe their responsibility towards individual patients is more important than their commitments towards future generations. Medical geneticists are faced with complex ethical conditions proportional to new achievements and some of these conditions will make future decisions and proceedings more complicated. A particular problem in medical genetics can be the principle of autonomy. On some occasions it is necessary to assess 
individual autonomy against good and bad practices related to close family members [17].

By assessing ethical principles derived from human genetics, the importance of this issue becomes clearer. Fundamental ethical principles defined by Tom Beauchamp and James Childress, American experts in ethical sciences, are based on four main principles:

Autonomy: Respect for individuals and their privacy rights, the importance of informed consent and confidentiality.

Benefit: Making decisions in favor of the patient.

Harmless: Not injuring the patient, improving the patient's and their family conditions.

Justice: Fairness in the distribution of available resources and facilities [18].

These principles were not applicable by themselves and were developed further by Jonson.

\section{Jonson's Criteria}

Recommendations for medical intervention, diagnosis validation, determination of treatment options and prognosis for each selected priority; is the patient competent? If so, what are their needs? If they are not competent, what is the patient's best interest?

Quality of life: Will the recommended treatment improve the patient's quality of life?

Underlying assumptions: Do religious, racial, cultural or legal aspects effect decisions? [19].

A more detailed plan based on the previous criteria presented by Mike Parker from the University of Oxford Ethox center is explained below:

What are the clinically relevant facts? For example, family activities, supporting general practitioners

What are the factors required for correct decisions? Who is responsible? When are decisions made? Who are involved in the decisions? What are procedural rules of confidentiality?

\section{A list of available options}

What are the important ethical attributes relevant to each option? For example, what does the patient's expectations? Is the patient competent? If not, what is the patient's best interest? What are the predicted consequences for each option?

What do laws or recommendations state about each option?

Ethical issues in favor and against each reasonable option must be determined.

Options must be selected based on the judgment of relative values for such reasoning. How are these issues compared? Are there any keywords (such as best personal interest) that should be agreed on their meanings? Are these discussions credible? Do these issues respect individuals? What are the consequences of these decisions that are implemented as general law?

The strongest reasons for rejecting arguments for each option must be identified.

Is the individual able to reject arguments? What are their reasons?
A decision should be made, reassessed based on true events and lessons must be learnt [20].

\section{Issues that Exist in Genetic Clinics and in Dealing with Patients}

\section{Autonomy}

The patient must have complete responsibility at the time of decision making. The degree to which this is possible depends on the quality of information presented. Sometimes, the patient only searches for guidance that ensures their decisions whereas the clinical expert or consultant should determine the level of guidance required for their condition [21].

\section{Informed decision}

The patient should be given the right to attain comprehensive information about all available options for their condition which also includes not wanting to make a decision. Consequences for each option must be explained. The medical team should not favor any option for the patient [22].

\section{Informed consent}

Honest and comprehensive information must be made available to the patient before carrying out any tests. This information includes risks details, limitations, applications and potential results for each option. Under current conditions, with respect to patient-doctor confidentiality, some signed consent forms for each operation exposed to the patient such as medical records, clinical photographs; genetic tests and DNA storage are kept. There are no legal requirements to attain agreements signed for blood tests where DNA is extracted. This issue was assessed by the UK Human Tissue Act in 2004. Based on this act, DNA which is obtained by biopsy samples or cellular material is not included as human tissue so there is no need for agreements whether the tissue is dead or alive. This act enables the necessity of formal agreements for cellular material to be used for genetic information for other individuals. The question is what damages are caused to the patient after using material which is an individual's unique identity for medical research and genetic diseases diagnosis? And if personal information which is considered private is compromised, who or which institution is considered responsible and how the patient can be compensated. In clinical genetics most of the patients under genetic assessments are children and individuals with learning difficulties who are not capable of giving informed consent. In addition, test results which have minimal benefits for the patient's treatment are still important for family members therefore decisions must be made that benefit patients' families in addition to the patient's best interest [23].

\section{Confidentiality (confidentiality of results)}

Test results and consultations must be kept confidential and most patients prefer to keep resulting data private. Guilt and shame may be associated with genetic diseases. Normally, confidentiality is violated under very specific conditions. For example when it is predicted that an individual's behavior may cause themselves or others harm. There are difficult issues to be addressed when sharing information and results from various medical genetics services [24]. 


\section{Genetic Counseling, Consanguineous Marriage and Ethical Challenges}

Human Geneticists define consanguineous marriages as marriages where couples are related as second cousins or are related closer. This type of marriage is considered a causative factor in the appearance of genetic disorders. Consanguinity is a vital subject of interest due to its high risk factors in causing various health problems. It is also a common cultural practice in some countries around the world such as Iran. Public health policies must consider consanguinity as one of its most important criteria $[3,4]$.

Over $20 \%$ of the human population resides in countries where consanguineous marriages are prioritized. Over $8.5 \%$ of children are the result of consanguineous marriages. Also, this type of marriage cause more cases of autosomal recessive disorders in children. The probability of congenital complications is almost 2.5 times higher for children of first cousins compared to parents who are not related [3].

According to our research; the main reasons for consanguineous marriages are social and cultural rather than religious beliefs. Public comprehension on genetic disorders related to consanguineous marriages must increase via media, physicians, scholars, nursing staff and society leaders $[3,4]$.

Around $80 \%$ of all people seeking premarital genetic counseling had consanguineous relations. Some of the less referral cases were related to preconception, pre and post natal genetic counseling. The most popular kind of consanguineous marriages were first cousin marriages (69\%). Family socioeconomic factors were not decisive in this type of marriage. Results conclude genetic counseling and media must increase public awareness so more people understand the risks related to consanguineous marriages. Also, ethical and moral principles should be taken into account $[3,4]$.

\section{Prenatal Diagnosis and Ethical Dilemmas}

The objective of prenatal diagnosis is not only to identify abnormalities in the fetus and to terminate the pregnancy if necessary, but it is to inform couples that risk giving birth to babies with genetic disorders of limitations and options available to them. A contentious debate in prenatal diagnosis is abortion which is not a good mental experience for the mother $[3,22,25]$.

\section{Postnatal Diagnosis and Ethical Dilemmas}

Technologies which may entail ethical issues include DNA microarray techniques and automatic mutation detection. These techniques may provide the possibility of widespread genetic screening at a cheap price for prenatal diagnosis. In some cases, parents want to be aware of their children carrying autosomal dominant diseases which occur in adulthood (such as Huntington's disease). In such cases, it should be determined whether these findings will help parents lead their children to education and employment opportunities or will rejecting their demands be considered denial of their parental rights. In other cases, parents request information about the carrier status of healthy siblings of a child with recessive disorder such as fibrosis. The problem with such requests is the abuse of the child's future autonomy. Tests must be delayed until the child reaches an age to make informed decisions. Also, if a child is aware of their illness from an early age, especially if their siblings are healthy, they may suffer detrimental effects such as the feeling of humiliation and frustration during their childhood. However, there is an agreement among genetic specialists that children should not be tested to determine their carrier status. The only case in which genetic testing on children is possible is when predictive tests may have beneficial medical effects for the children. This condition is met for issues such as familial hypercholesterolemia and phenylketonuria. In such situation, early monitoring of food consumption may be beneficial. Also, in some predisposing familial cancer syndromes, early treatment and preventive surgery can take place if there are early indications [25].

One of the reasons for opposing tests on children for detecting viral diseases that will appear in adulthood is parents biased behavior towards their children. There is also a similar case for PGD where the embryo is not only tested for fanconi syndrome, but to potentially use stem cells for siblings who are infected. People who use this technology view children as tools or consumers. In addition, children who are created this way, have no idea about their tissue donation to their siblings [25].

\section{Genetic Tests and Involvement of Other Family Members}

If the diagnosis of disorder in other family members can also create conflicts, further tests are proposed for all family members. Confidentiality is an important moral issue here. Medical Geneticist must have permission to carry out these tests. In some cases, the patient does not permit such information to be disseminated. In this situation, Medical Geneticist often try to convince their patients about the importance of sharing information with relatives and also explain the consequences and frustration that may be observed in the future of a child which are preventable by predicting such diseases. In many cases, elaborate and detailed advice will lead to a satisfactory solution. Finally, many clinical geneticists prefer to be their patient's confidant rather than share their medical information. Although, not everyone agrees with this way of thinking because it may lead to the disability or death of other family members therefore experts seek to persuade individuals to disclose their information. This perspective is supported by decision making working groups such as the Nuffield Council on Bioethics. Sometimes, in extreme circumstances that endanger other family members, information may be disclosed by general practitioners [26].

\section{Genetics Tests and Insurance Companies}

Insurance companies are concerned with individuals with positive predictive testing who do not reveal their test results. The medical genetics community is concerned with discrimination against people with positive test results to an extent that they may be denied insurance. This concern is with people with late onset of the disease since they may be denied insurance if their test results are positive. This has led to legal restrictions approved on the use of genetic information by health insurance in the United States. In 1999, insurance companies in the UK stated a vision and by reassessing their lists, they declared that genetic testing will not be carried out on applicants or genetic testing results will not be recorded in their job applications only if their life insurance is not over a hundred thousand pounds [27,28]. In 2005, the UK government negotiated with the English insurance community over limitations on using predictive genetic tests by insurers until November 2011 [29]. A new written agreement titled 'agreement and moratorium on genetics and insurance' was introduced which states no individual is required to disclose predictive test results unless approved by the government 
Page 5 of 5

committee for genetics and insurance. Disclosure of such information is permitted for life insurance which is over five hundred thousand pounds and for sickness insurance, emergency support or income of over three hundred thousand pounds [30].

\section{Screening, Genetics Tests and Social Rights}

Different cultures of societies respond differently to screening programs in order to provide informed choices, consents and guaranteeing autonomy. Commensurate with the level of knowledge, freedom and security in society, screening results will differ and beneficial results cannot be expected for individuals from societies where they do not feel secure. Even with strong recommendations for carrier screening tests, individuals should be treated in such a way that they feel these screenings are entirely optional. If test results are positive, counseling is essential to minimize any sense of shame and humiliation. Confidentiality of screening test results is essential because positive results may jeopardize individuals' careers or cause humiliation in society (school, work place, family etc). These concerns lead to a resolution by the Equal Opportunities Committee in 1995 which states that expelled employees who are susceptible to diseases should be supported by the American Disabilities Act [31].

\section{Conclusion}

Ethical issues are of great importance in medical genetics. Due to the ever increasing advances in medical genetics and innovation on genetics diagnostic methods, awareness on human genome is increasing and new known genes associated with human diseases are discovered which entail new responsibilities along with legal and ethical issues. Individuals are concerned with the exposure of their genetic information which increases the possibility of abuse and threatens the security of some people's lives. Specifically, the medical genetics community plays a key role in balancing the needs of patients and families and by effective performance may enable advances in diagnostic and therapeutic procedures while ensuring the safety and privacy of patients by keeping their medical information confidential. Nevertheless, medical genetics is not able to respond to ethical issues and dilemmas alone and problems will be encountered in different societies with different cultures, beliefs and religions which must be addressed accordingly. Responsibilities of medical genetics are increasing to ensure the interests of patients and families.

\section{References:}

1. Bereshneh HA, Nabavi SA (2014) Medical Genetics, Criteria of Miscarriage and Ethical Challenges of Genetic Tests. Genetics in the 3rd Millennium 12: 3478-3487.

2. Fulda KG, Lykens K (2006) Ethical issues in predictive genetic testing: a public health perspective. J Med Ethics 32: 143-147.

3. Fathzadeh M, Babaie Bigi MA, Bazrgar M, Yavarian M, Tabatabaee HR, et al. (2008) Genetic counseling in southern Iran: consanguinity and reason for referral. J Genet Couns 17: 472-479.

4. Akrami SM, Osati Z (2007) Is consanguineous marriage religiously encouraged? Islamic and Iranian considerations. J Biosoc Sci 39: 313-316.

5. Pletcher BA, Toriello HV, Noblin SJ, Seaver LH, Driscoll DA, et al. (2007) Indications for genetic referral: a guide for healthcare providers. Genet Med 9: 385-389.

6. Genetic Alliance, District of Columbia Department of Health (2010) Understanding Genetics: A District of Columbia Guide for Patients and Health Professionals. Washington (DC): Genetic Alliance.
7. Donev D (2013) Principles and ethics in scientific communication in biomedicine. Acta Inform Med 21: 228-233.

8. Parker M, Lucassen AM (2004) Genetic information: a joint account? BMJ 329: 165-167.

9. Parker M, Ashcroft R, Wilkie AO, Kent A (2004) Ethical review of research into rare genetic disorders. BMJ 329: 288-289.

10. Burgess MM, Laberge CM, Knoppers BM (1998) Bioethics for clinicians: 14. Ethics and genetics in medicine. CMAJ 158: 1309-1313.

11. Diekelmann N, Diekelmann J (2000) Learning ethics in nursing and genetics: narrative pedagogy and the grounding of values. J Pediatr Nurs 15: 226-231.

12. Edwin B (2003) "War against the weak: Eugenics and America's campaign to create a master race." New York.

13. Collins FS, Patrinos A, Jordan E, Chakravarti A, Gesteland R, et al. (1998) New goals for the U.S. Human Genome Project: 1998-2003. Science 282: 682-689.

14. Burgess MM (2001) Beyond consent: ethical and social issues in genetic testing. Nat Rev Genet 2: 147-151.

15. MacDonald C, Williams-Jones B (2002) Ethics and genetics: susceptibility testing in the workplace. J Bus Ethics 35: 235-241.

16. National Society of Genetic Counselors' Definition Task Force, Resta R, Biesecker BB, Bennett RL, Blum S, et al. (2006) A new definition of Genetic Counseling: National Society of Genetic Counselors' Task Force report. J Genet Couns 15: 77-83.

17. Richard L (1996) Dysgenics: Genetic deterioration in modern populations. Ulster Institute for Social Research, UK.

18. Beauchamp TL, Childress JF (2001) Principles of biomedical ethics. Oxford university press, UK.

19. Lee MA, Cassel CK (1984) The ethical and legal framework for the decision not to resuscitate. West J Med 140: 117-122.

20. Parker M, Lucassen AM (2004) Genetic information: a joint account? BMJ 329: 165-167.

21. Hallowell N, Foster C, Eeles R, Jones AA, Murday V, et al. (2003) Balancing autonomy and responsibility: the ethics of generating and disclosing genetic information. J Med Ethics 29: 74-79.

22. Marteau TM (1995) Towards informed decisions about prenatal testing: a review. Prenat Diagn 15: 1215-1226.

23. Hunt LM, de Voogd KB (2007) Are good intentions good enough? Informed consent without trained interpreters. J Gen Intern Med 22: 598-605.

24. Harris M, Winship I, Spriggs M (2005) Controversies and ethical issues in cancer-genetics clinics. Lancet Oncol 6: 301-310.

25. Dondorp W, Sikkema-Raddatz B, de Die-Smulders C, de Wert G (2012) Arrays in postnatal and prenatal diagnosis: An exploration of the ethics of consent. Hum Mutat 33: 916-922.

26. Billings PR, Kohn MA, de Cuevas M, Beckwith J, Alper JS, et al. (1992) Discrimination as a consequence of genetic testing. Am J Hum Genet 50: 476-482.

27. Harper PS (1993) Insurance and genetic testing. Lancet 341: 224-227.

28. Angus MS (1999) Modeling the impact of genetics on insurance. North American Actuarial Journal 3: 83-101.

29. Mayor S (2005) UK insurers postpone using predictive genetic testing until 2011. BMJ 330: 617.

30. Mark RA, Joly Y (2009) Genetic information and insurance underwriting. In: Atkinson P, Glasner P, Lock M (eds.) Handbook of Genetics \& Society: Mapping the New Genomic Era. Routledge Taylor \& Francis, UK, p. 127.

31. Clare W, Alderson P, Farsides B (2002) Drawing the line in prenatal screening and testing: Health practitioners' discussions. Health, Risk \& Society 4: 61-75. 